\title{
Climate Characteristics of the CWB Global Forecast System: Hydrological Processes and Atmospheric Circulation
}

\author{
Jau-Ming Chen ${ }^{1}$, Chin-Tzu Fong ${ }^{1}$, Feng-Ju Wang ${ }^{1}$, Chih-Hui Shiao ${ }^{1}$, \\ Jen-Her Chen ${ }^{1}$ and Ming-Deng Cheng ${ }^{1}$
}

(Manuscript received 15 August 1998, in final form 13 October 1999)

\begin{abstract}
The purpose of this paper is to document the climate characteristics of the Global Forecast System (GFS), which is an atmospheric general circulation model developed at the Central Weather Bureau (CWB), Taiwan. This paper documents the winter (December-February) and summer (JuneAugust) climate characteristics of simulated hydrological processes and atmospheric circulation from a 2-year control simulation conducted with the GFS using an annually repeating prescribed sea surface temperature climatology.

In most regards, the climate characteristics of hydrological processes and atmospheric circulation are reproduced reasonably well by the GFS when compared to observations and analyses of the atmosphere. As for the climate characteristics of hydrological processes, the major features of observed precipitation, such as the Intertropical Convergence Zone (ITCZ), the Asian monsoon regimes, and the extratropical storm tracks, are well captured in the GFS simulation. Similarly, other climate features of observed precipitation, namely the regions of low precipitation rates over the subtropical subsidence zones and polar areas, are also well defined by the GFS.

The simulated precipitation pattern, however, exhibits some obvious discrepancies from the observed in the tropics. Excessive precipitation is simulated by the GFS over some tropical regions where there are complex topographic variations among oceans and lands. Otherwise, the GFS precipitation in the remaining tropical regions is generally underestimated. In particular, the underestimate of model precipitation over the tropical eastern Pacific results in a local ITCZ that is less organized in spatial structure than the observed. This model precipitation deficiency is linked to underestimates of precipitable water content and water vapor convergence over the tropical eastern Pacific in the GFS simulation.

Regarding the climate characteristics of the zonal mean state, the zonal
\end{abstract}

${ }^{1}$ Research and Development Center, Central Weather Bureau, Taipei, Taiwan, ROC 
mean climatologies of temperature and zonal wind are adequately simulated by the GFS when compared to analyses. The major difference between the simulated and analyzed zonal mean temperatures is a systematic cold bias in the model troposphere. This cold bias is generally within $4^{\circ} \mathrm{K}$ of the analyses for most of the tropospheric domain bounded by $40^{\circ} \mathrm{S}$ and $40^{\circ} \mathrm{N}$. The model cold bias becomes significant at the polar tropopause, where the simulated zonal mean temperature can be from $8^{\circ} \mathrm{K}$ to $1^{\circ} \mathrm{K}$ colder than the analyzed. Also noteworthy is the spatial relationship between the zonal mean temperature bias and zonal mean zonal wind bias. This is found to be consistent with the spatial relationship between the real temperature and the real zonal wind fields known as the thermal wind relationship. This finding suggests that interactions between the thermal and dynamic fields in the GFS simulation must be to a great extent consistent with analyses with regard to the thermal wind relationship.

Regarding the climate characteristics of atmospheric circulation, the primary circulation features associated with the summer monsoon system and winter teleconnection pattern are well represented in the GFS simulation when compared with analyses. Nevertheless, in winter, major differences between the analyzed and simulated circulation fields include the underestimate of the East Asia subtropical jet features and the overestimate of the North America subtropical jet features in the GFS simulation. In the summer simulation, the major circulation bias is that the zonal wavenumber-2 component of the Northern-Hemisphere stationary eddy is simulated with larger amplitude than analyses. This circulation bias is accompanied by excessive precipitation biases over the subtropical central North Pacific west of the date line and the Central America/Caribbean Sea region.

(Key words: Climate characteristics, Global Forecast System, Control simulation, Hydrological processes, Atmospheric circulation)

\section{INTRODUCTION}

For any meteorological operational center, such as the Central Weather Bureau (CWB) in Taiwan, one of the major missions is to issue weather forecasts. A successful forecast depends heavily upon two factors: prediction results from the numerical weather prediction (NWP) model and the experience gained by forecasters from making good use of observations and model results. Thus, improving the performance of the NWP model has always been a pivotal task in the operational center. Generally speaking, an NWP model is built to simulate the atmospheric state based upon our best knowledge of the dynamic and physical processes of the atmosphere. However, the atmosphere itself is such an elaborate system that its intricacy limits our understanding of this system. Most NWP models can only capture certain degrees of 
actual atmospheric phenomena. Systematic biases are commonly found between the model's atmospheric states and actual atmospheric states. Such biases become more evident as the numerical predictions or simulations are integrated into time scales longer than medium range (1-2 weeks). This is because the climatological balance of the forecast system becomes primarily important in determining the model regime in these time scales (Hollingsworth et al., 1980; Bengtsson and Simmons 1983). In other words, the model regime drifts into its own climate state that is primarily affected by the numerical characteristics of the NWP system and is thus different from the real atmosphere. A clear understanding of model climate states and model systematic biases might shed light on how best to reduce the model bias and improve the model performance. Therefore, having insight on the climate characteristics of the model is essential in the development of an NWP model.

Since the 1980s, the CWB started to develop an atmospheric general circulation model (AGCM), namely the Global Forecast System (GFS). The GFS was originally designed to provide in-time large-scale background fields for operations of its companion limited-area model (Jeng et al., 1991) and the typhoon track forecast model (Peng et al., 1993). It was also intended to provide references for less than one-week forecasts. It is clear that a more skillful GFS would enhance the overall performance of the CWB's operations. Accordingly, continuous efforts have been made by the CWB NWP group to improve the forecast skills of the GFS.

The purpose of this paper is to report on the progress from one of these efforts. This paper will describe the climate characteristics of the simulated hydrological processes and atmospheric circulation from a 2-year control simulation conducted with the GFS using an annually repeating prescribed sea surface temperature (SST) climatology. Climate characteristics of the other model processes, such as planetary boundary layer processes and radiation processes, will be reported in future studies.

The outline of this paper is as follows. Section 2 briefly describes the standard configuration of the GFS and the design of the control simulation conducted in this study. The observed and analyzed data used to validate the control simulation are introduced in Section 3. Section 4 outlines the climate characteristics of the hydrological processes simulated by the GFS. Climate characteristics of the zonal-mean state and atmospheric circulation simulated by the GFS are examined in Sections 5 and 6, respectively. Concluding remarks are presented in Section 7.

\section{THE GFS MODEL AND THE CONTROL SIMULATION}

The version of the CWB GFS used in this study is at T42 (triangular truncation at wavenumber 42) horizontal resolution (about $2.8^{\circ}$ longitude $\times 2.8^{\circ}$ latitude) and with 18 sigma levels in the vertical $(1.00000,0.98937,0.96678,0.93222,0.87558,0.80182,0.71594,0.62292$, $0.52774,0.43538,0.35083,0.27907,0.21528,0.15947,0.11163,0.07176,0.03987$, and 0.01595). The GFS uses a primitive equation (PE) model as its forecast model which includes vertical vorticity, horizontal divergence, surface pressure, virtual potential temperature, and specific humidity as prognostic variables.

The GFS comprises schemes to parameterize specific physical processes, namely surface 
fluxes, vertical turbulence mixing, shortwave and longwave radiative transfer, cumulus convection, large-scale condensation, and gravity wave drag. In the GFS, surface fluxes are calculated with Louis (1979) formulas that are empirical approximations of the similarity theory results of Monin and Obukhov (1954). The vertical turbulence mixing is parameterized by computing eddy mixing fluxes in a form of the K-theory scheme as developed by Detering and Etling (1985). Radiative transfer is calculated following the parameterization scheme proposed by Harshvardhan et al., (1987). This includes a longwave and shortwave radiative transfer calculation that considers the effects of fractional clouds in radiative fluxes. The cumulus convection is parameterized by a relaxed form of the Arakawa-Schubert convection scheme (Arakawa and Schubert, 1974) following Moothi and Suarez (1992). The nonprecipitatingtype shallow convection parameterization, developed by Tiedtke (1984), is built into the model to parameterize the effects of surface-forced shallow convection in a conditionally unstable layer near the surface. The GFS also includes a large-scale condensation scheme to condense the supersaturated water vapor into liquid water. This condensed liquid water which reaches the surface is referred to as large-scale precipitation. A gravity wave drag parameterization developed by Palmer et al., (1986) is used to represent the effect of vertical momentum flux associated with gravity waves triggered by subgrid-scale terrain. For more details of the dynamic and physical schemes of the GFS, readers are referred to Liou et al. (1997).

The control simulation conducted with the GFS has been integrated for about 2 years ( 26 months) of model time, using an annually repeating prescribed SST climatology compiled by the Atmospheric Model Intercomparison Project (AMIP, Gate 1992). This simulation uses an initial state derived from the CWB analysis data of 15 January 1995. The time step of this control simulation is 15 minutes.

\section{VALIDATING DATA}

The observed and analyzed data used to validate the simulation results are: (a) the global precipitation estimates compiled by Xie and Arkin (1996) from gauge observations and several different satellite retrieval estimates and (b) the hydrological variables and upper-air wind fields analyzed by the National Centers for Environmental Prediction/National Center for Atmospheric Research (NCEP/NCAR) reanalysis project (hereafter referred to as the NCEP data, Kalney et al., 1996). Both sets of validating data cover the period 1979-1995. In this study, the winter (December-February) and summer (June-August) climatologies of the 2-year control simulation are validated against the respective winter and summer climatologies of the 19791995 validating data.

\section{HYDROLOGICAL PROCESSES}

The hydrological processes of the atmosphere are often portrayed using the water-budget equation:

$$
\partial \mathrm{W} / \partial \mathrm{t}+\nabla \bullet \mathrm{Q}=\mathrm{E}-\mathrm{P},
$$


where $\mathrm{W}=(1 / \mathrm{g}) \int_{0}^{\mathrm{po}} \mathrm{qdp}$ is the precipitable water of the atmosphere; $\mathrm{Q}=(1 / \mathrm{g}) \int_{0}^{\mathrm{po}}(\mathrm{Vq}) \mathrm{dp}$ is the horizontal flux of water vapor; and $\mathrm{q}, \mathrm{V}, \mathrm{p}_{0}, \mathrm{E}$, and $\mathrm{P}$ are specific humidity, horizontal velocity, surface pressure, evaporation, and precipitation, respectively. Among the hydrological variables shown in the water-budget equation, precipitation is the most meaningful with regard to climate dynamics. Since the latent heat released by tropical precipitation contributes the primary source to tropical heating (e.g., Kasahara 1982; Kasahara and Mizzi 1985). Furthermore, tropical heating has been found to play a significant role in determining the global circulation regimes in summer (e.g., Ting 1994) and winter (e.g., Hoskins and Karoly 1981; Simmons 1982). The above results imply that in climate simulation, a better simulation of the precipitation field may be linked to a better simulation of atmospheric circulation. It has also been reported in previous studies that in the water budget equation, precipitation is primarily maintained by the convergence of the large-scale water vapor flux, rather than by the local enhanced evaporation (e:g., Deser and Wallace 1990; Mo and Higgins 1996). Based upon the results mentioned above, subsequent discussions of the climate characteristics of simulated hydrological processes focus on the areas of precipitation, precipitable water, and water vapor flux.

\subsection{Zonal Mean Precipitation}

The climatologies of zonal mean precipitation for the GFS simulation (denoted as $\mathrm{P}_{z}(\mathrm{GFS})$ ) and the observational estimates by Xie and Arkin (1996) [denoted as $P_{z}(X A)$ ] are shown in Figs. $1 \mathrm{a}$ and $1 \mathrm{~b}$ for winter and summer, respectively. In winter, there is reasonable agreement between $\mathrm{P}_{z}(\mathrm{GFS})$ and $\mathrm{P}_{\mathrm{z}}(\mathrm{XA})$ in terms of magnitude and positions of the tropical precipitation maxima over the Intertropical Convergence Zone (ITCZ), the subtropical precipitation minima over the subtropical subsidence zones, the extratropical secondary maxima over the midlatitude storm track regions, and the polar precipitation minima over the high latitudes. Discrepancies between $P_{z}(G F S)$ and $P_{z}(X A)$ are in fact generally insignificant, except in the midlatitudes and tropics of the SH. Figure la shows that compared with $\mathrm{P}_{\mathrm{z}}(\mathrm{XA}), \mathrm{P}_{\mathrm{z}}(\mathrm{GFS})$ is overestimated over the SH midlatitude storm track regions (around $50^{\circ} \mathrm{S}$ ) but underestimated over the ITCZ south of the equator (around $10^{\circ} \mathrm{S}$ ). In summer, Fig. $1 \mathrm{~b}$ shows that $\mathrm{P}_{\mathrm{z}}(\mathrm{GFS})$ generally agrees well with $\mathrm{P}_{\mathrm{z}}(\mathrm{XA})$ in magnitude and the shape of the latitudinal distribution. Fig. 1b, though, does show that discrepancies between $\mathrm{P}_{z}$ (GFS) and $\mathrm{P}_{z}(\mathrm{XA})$ are more noticeable in two regions: $0^{\circ}-30^{\circ} \mathrm{N}$ and $30^{\circ} \mathrm{S}-60^{\circ} \mathrm{S}$. In the former, $\mathrm{P}_{z}(\mathrm{GFS})$ is underestimated over the ITCZ between $0^{\circ}-15^{\circ} \mathrm{N}$, but overestimated in the $15^{\circ}-30^{\circ} \mathrm{N}$ region when compared to $P_{z}(X A)$. In the $30^{\circ} \mathrm{S}-60^{\circ} \mathrm{S}$ region, the midlatitude precipitation maximum center is simulated $10^{\circ}$ latitude too far south by the GFS than the observed.

To evaluate the degree of resemblance between the simulated and observed zonal mean precipitation fields, the pattern correlation between these two fields is computed. To do so, each spatial data set is multiplied by an area-weighted factor to take into account the fact that the area size of the data grid point varies with latitude. The pattern correlation between the $P_{z}(G F S)$ and $P_{z}(X A)$ series shown in Fig. 1 is 0.98 for winter and 0.93 for summer. It is apparent that, with regard to spatial distribution, the zonal mean precipitation simulated by the 

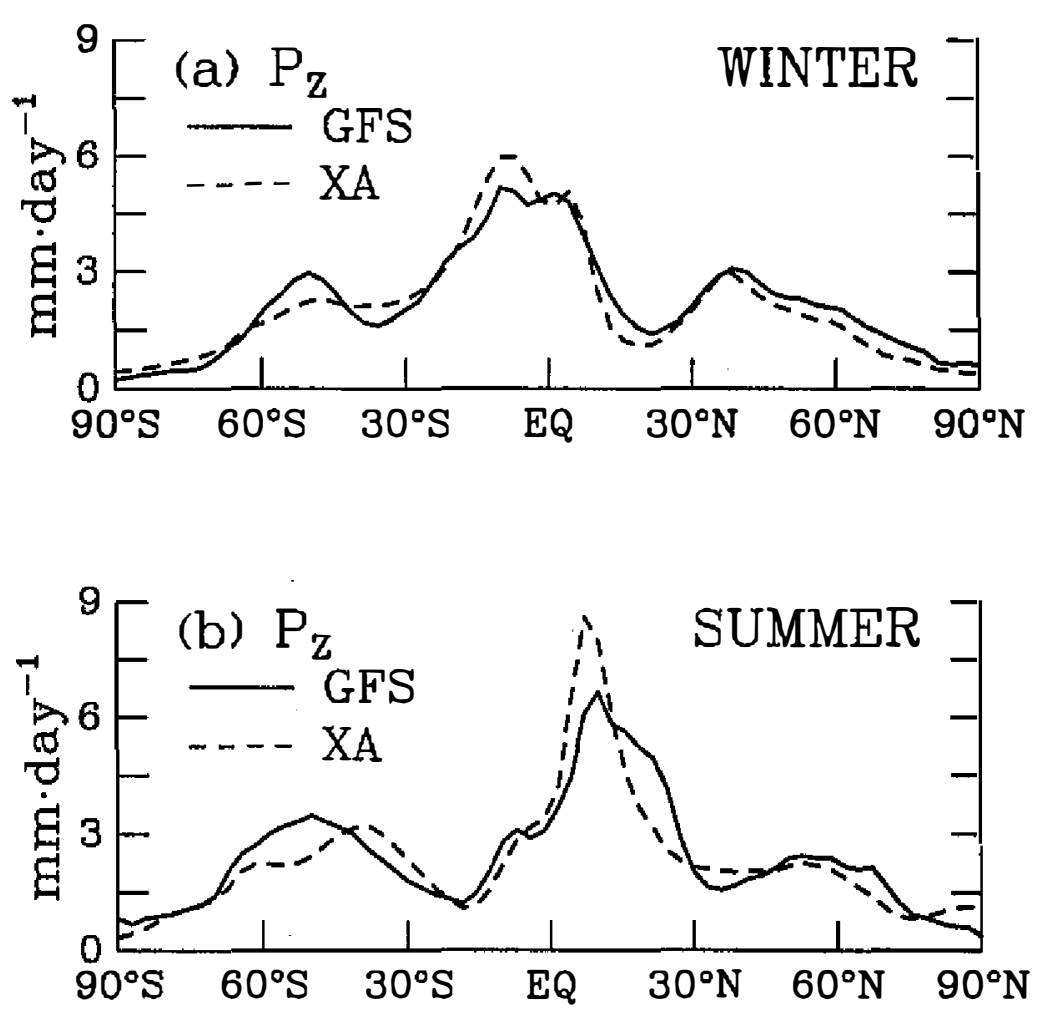

Fig. 1. (a) Winter and (b) summer climatologies of zonal mean precipitation for the GFS simulation $\left(\mathrm{P}_{z}(\mathrm{GFS})\right)$ and the observational estimates of Xie and Arkin (1996) $\left(\mathrm{P}_{\mathrm{z}}(\mathrm{XA})\right)$.

GFS is rather consistent with the observed in both winter and summer. Also revealed by the pattern correlation is that $P_{z}(G F S)$ is in better agreement with $P_{z}(X A)$ in winter than summer.

In addition to spatial distribution, we are also concerned about whether the total amount of precipitation is properly simulated in the GFS simulation. Therefore, the global mean precipitation of the GFS simulation is compared with the observed. The global mean precipitation is $2.68 \mathrm{~mm} /$ day in winter for the GFS simulation and $2.64 \mathrm{~mm} /$ day for the observed. In summer, the simulated and observed global mean precipitation is $2.83 \mathrm{~mm} /$ day and $2.78 \mathrm{~mm} /$ day, respectively. The difference between the simulated and observed global mean precipitation, $0.04 \mathrm{~mm} /$ day in winter and $0.05 \mathrm{~mm} /$ day in summer, is within $2 \%$ of the observed values. It is clear that the total amount of precipitation (as inferred from global mean precipitation) is properly simulated by the GFS when compared to observational estimates.

\subsection{Global Precipitation Distribution}

The climatological global precipitation distributions for the GFS simulation [denoted as 
$\mathrm{P}(\mathrm{GFS})$ ], the Xie and Arkin estimates [denoted as $\mathrm{P}(\mathrm{XA})$ ], and the difference between the GFS simulation and Xie and Arkin estimates [(P(GFS) minus P(XA), denoted as P(GFS-XA)] are illustrated in Figs. 2 and 3 for winter and summer, respectively. Overall, the principal features of the observed precipitation distribution are well reproduced by the GFS in the largescale sense. In winter, relative to the observed, the principal extratropical precipitation features associated with storm tracks over the North Pacific, North Atlantic, and the SH oceans in the $45^{\circ} \mathrm{S}-60^{\circ} \mathrm{S}$ zone are simulate at proper locations and magnitude by the GFS. In the tropics, the major observed precipitation features, such as the ITCZ, the South Pacific Convergence Zone (SPCZ), and three continental precipitation zones (Africa, the maritime continents north of Australia, and South America), are also represented reasonably well in the GFS simulation. In the subtropics, the dominant observed precipitation features associated with the regions of low precipitation rates over the subtropical subsidence zones are also well defined in the GFS simulation. Despite such closeness in those findings, there are some notable discrepancies between the simulated and observed precipitation distributions as indicated by the P(GFS$\mathrm{XA}$ ) field. Differences between the $\mathrm{P}(\mathrm{GFS})$ and $\mathrm{P}(\mathrm{XA})$ fields tend to be more significant in the tropical regions, with major excessive precipitation errors in the GFS simulation over the four tropical regions in Madagascar southeast of Africa, the maritime continents north of Australia, the oceans off the west coast of Central America, and the oceans off the northeast coast of South America. It is interesting to note that these excessive precipitation errors are located in tropical areas where there are complex topographic contrasts between the oceans and lands. The simulation of excessive precipitation over these heterogeneous tropical regions was also previously found in climate simulations using the NCAR community climate model (CCM) (Hack et al., 1994) and the AMIP models (Lau et al., 1996). Apart from these overestimated regions, GFS precipitation in the remaining tropical regions is generally underestimated. The $\mathrm{P}(\mathrm{GFS}-\mathrm{XA})$ distribution shows that the GFS precipitation is substantially underestimated in the ITCZ along the equatorial Pacific, the plateau over southern Africa, the tropical islands northwest of Australia, and the northern and central sectors of South America. In addition to the underestimate of model precipitation, the simulated ITCZ strip over the tropical eastern Pacific (Fig. 2a) is less organized in terms of spatial pattern than the observed (Fig. 2b). Moreover, the model continental precipitation is generally weaker in magnitude than the observed over Africa, Australia, and South America (Fig. 2c).

In summer, the major features of observed precipitation, such as the extratropical storm tracks, the ITCZ, the SPCZ, and the Asian summer monsoon regimes, are well captured by the GFS in the large-scale sense. Another large-scale precipitation feature is associated with regions of low precipitation rates in the subtropics with well-defined minima in the eastern oceans. This feature is also well represented in the GFS simulation. On the other hand, there are some obvious discrepancies between the observed and simulated precipitation fields, particularly in the tropics. As shown in the P(GFS-XA) field (Fig. 3c), the GFS precipitation in the tropics is overestimated over the oceans east of Africa, the Bay of Bengal, the maritime continents north of Australia, and the Central America/Caribbean Sea region. Similar to the case with winter simulation, the above overestimated precipitation biases are located in the vicinity of tropical regions with heterogeneous topography. In contrast, the GFS precipitation 

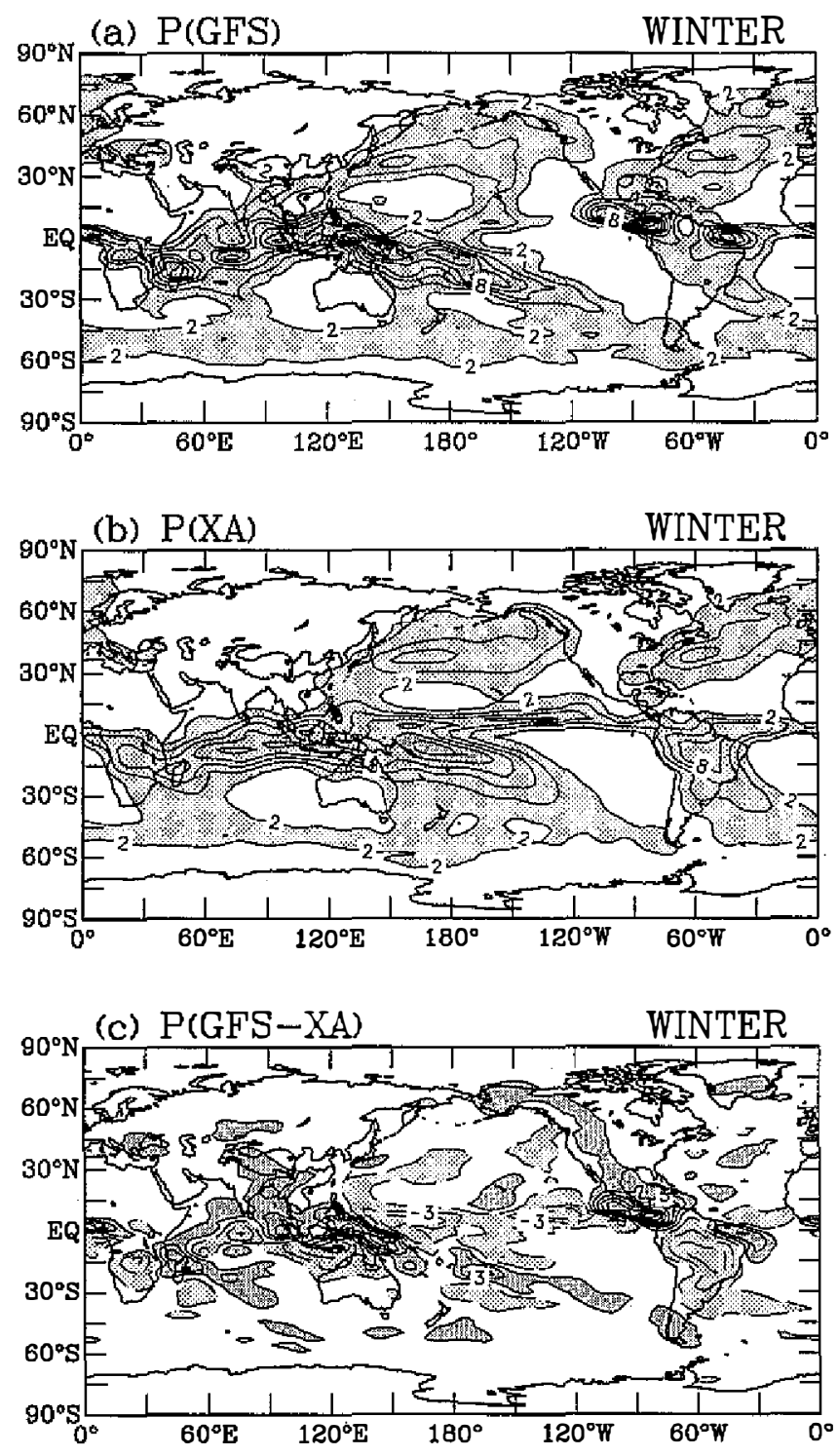

Fig. 2. Horizontal distributions of winter precipitation for (a) the GFS simulation (P(GFS)), (b) the observational estimates of Xie and Arkin (P(XA)), and (c) the difference between the GFS simulation and Xie and Arkin estimates ( $\mathrm{P}(\mathrm{GFS})$ minus $\mathrm{P}(\mathrm{XA})$, denoted as $\mathrm{P}(\mathrm{GFS}-\mathrm{XA})$ ). All the precipitation contour intervals are $2 \mathrm{~mm} /$ day. In (a) and (b), precipitation values larger than $10 \mathrm{~mm}$ day are heavily shaded, and those between 2 and $10 \mathrm{~mm} /$ day are lightly shaded. In (c), precipitation values larger than $1 \mathrm{~mm} /$ day are heavily shaded, and those smaller than $-1 \mathrm{~mm} /$ day are lightly shaded. 

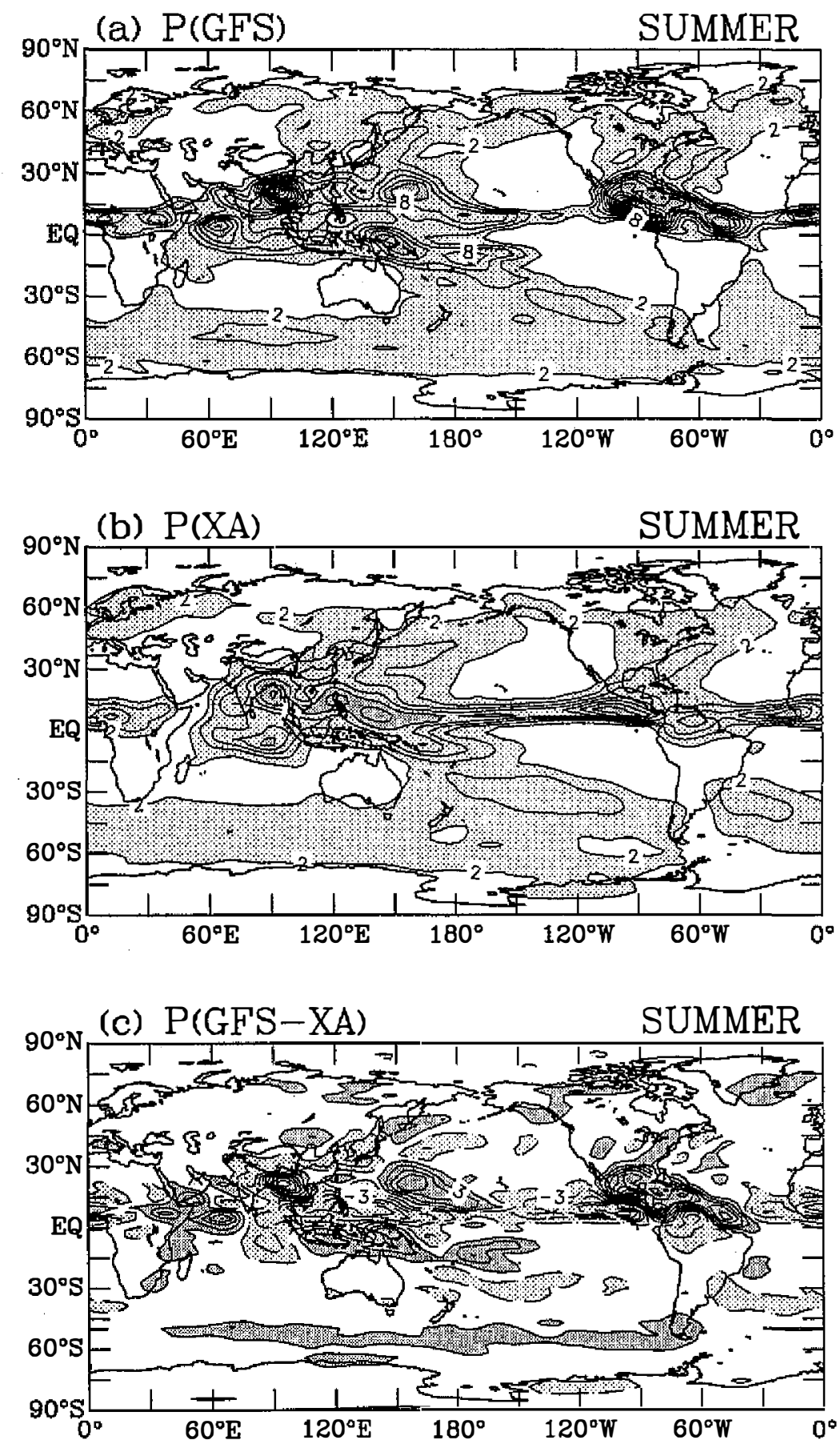

Fig. 3. As in Figure 2, except for the horizontal distributions of summer precipitation. 
is underestimated over the Asian monsoon region (except over the Bay of Bengal), the ITCZ along the tropical Pacific, and South America. In the extratropics, discrepancies between the observed and simulated precipitation fields are generally not significant.

Pattern correlations are computed to evaluate the degree of resemblance between the observed and simulated precipitation distributions. For the global domain, the pattern correlation between the $\mathrm{P}(\mathrm{XA})$ and $\mathrm{P}(\mathrm{GFS})$ fields is 0.81 for winter and 0.74 for summer. As inferred from these pattern correlations, the global precipitation distribution simulated by the GFS has better agreement with the observed in winter than in summer. Of note is that the GFS zonalmean precipitation is also in better agreement with the observed in winter.

Discussions in this section reveal some systematic biases in the GFS precipitation field which portray some unique properties of the GFS model. In the tropics, the GFS precipitation is underestimated over the central-Pacific warm pool in winter and over the Asian monsoon region (except over the Bay of Bengal) and the western Pacific in summer. These underestimated regions are over the major climatological centers of tropical heating (or tropical convection) in winter and summer. Considering the major contributor to tropical heating is the latent heat released by tropical precipitation, these underestimates imply that the GFS tropical heating over its climatological center in the Asia-Pacific region may be weaker in intensity than the actual tropical heating. In the extratropics, the precipitation biases are not evident in the storm track regions. In other words, the extratropical precipitation simulated by the GFS is in good agreement with the observed. Hack et al., (1994) reported that in the CCM the latent heat associated with extratropical precipitation is mainly brought on by large-scale condensation. If so, then we can infer that when compared with the observed, the large-scale condensation scheme included in the GFS model performs adequately with regard to the simulation of extratropical precipitation.

\subsection{Precipitable Water and Water Vapor Flux}

In this section, climate characteristics of the atmospheric moisture fields are examined from the fields of precipitable water (W) and the divergent components of horizontal water vapor flux $\left(\mathrm{Q}_{D}=\nabla\left[\nabla^{-2}(\nabla \cdot \mathrm{Q})\right]\right.$ ). The winter and summer climatologies of $\mathrm{W}$ (shown in contour) and $Q_{D}$ (shown in vector) for the GFS simulation and the NCEP data are illustrated in Fig. 4. The principle features of climatological moisture fields are located in the tropics. In winter, the GFS $Q_{D}$ field (Fig. 4a) indicates that the major meridional transport of moisture is from the $\mathrm{NH}$ tropics into the $\mathrm{SH}$ tropics. With the convergence of moisture in the $\mathrm{SH}$ tropics, the winter $\mathrm{W}$ field simulated by the GFS exhibits elongated maximum centers across the $\mathrm{SH}$ tropical regions between the Indian Ocean and the western Pacific. In summer (Fig. 4c), the meridional transport of moisture simulated by the GFS becomes northward from the SH tropics into the NH tropics. With the moisture convergence in the NH tropics, the GFS summer W field shows maximum centers over the $\mathrm{NH}$ tropical oceans adjacent to the Asian continent, the eastern-Pacific ITCZ, and the Central America/Caribbean Sea region.

The above seasonal variations in meridional moisture transport and the locations of precipitable water maximum centers in the GFS simulation are in good agreement with that which is depicted by the NCEP analyzed moisture fields in Figs. $4 \mathrm{~b}$ and $4 \mathrm{~d}$. In fact, the structure and 

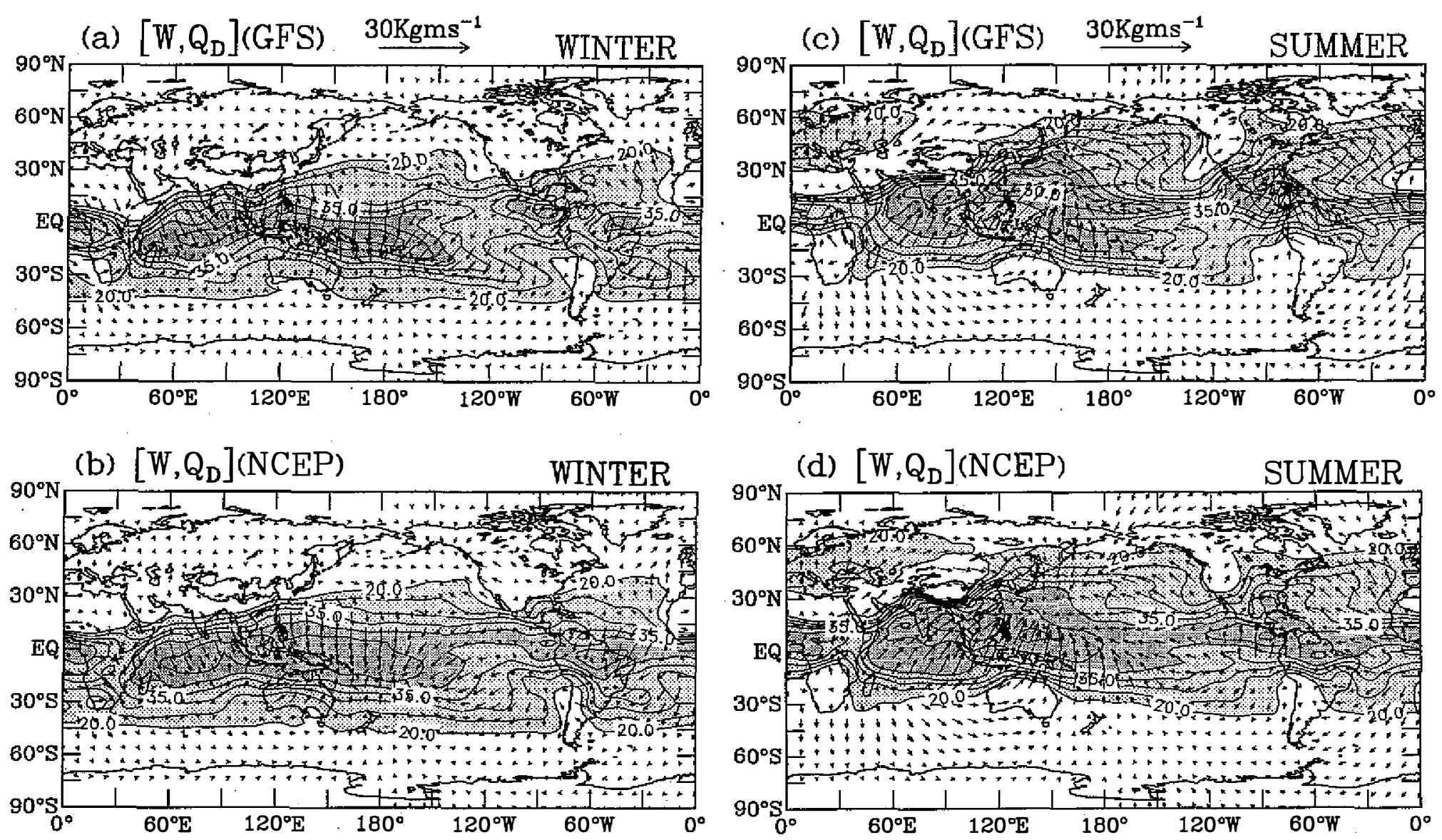

Fig. 4. Global distributions of precipitable water (W, shown in contours) and the divergent component of horizontal water vapor flux $\left(Q_{D}\right.$, shown in vectors) for (a) the GFS winter climatology; (b) the NCEP winter climatology; (c) the GFS summer climatology; and (d) the NCEP summer climatology. All contour intervals of precipitable water are $5 \mathrm{Kg} / \mathrm{m}^{2}$. Precipitable water values larger than $40 \mathrm{Kg} / \mathrm{m}^{2}$ are heavily shaded, and those between 20 and $40 \mathrm{Kg} / \mathrm{m}^{2}$ are lightly shaded. 
magnitude of the analyzed moisture fields are generally well represented in the GFS simulation. Regarding the difference between the simulated and analyzed moisture fields, one important feature to note is the moisture bias over the eastern-Pacific ITCZ. Over the tropical eastern Pacific at around $150^{\circ} \mathrm{W}-90^{\circ} \mathrm{W}$, the GFS precipitable water field is underestimated. This is accompanied with less convergence of water vapor flux and an underestimate of precipitation (Figs. $2 \mathrm{c}$ and $3 \mathrm{c}$ ) over the tropical eastern Pacific in the GFS simulation when compared to analyses. These relationships suggest that in the GFS simulation, the amount of transport of moisture into the eastern-Pacific ITCZ is less than in the analyzed, and consequently less precipitation can be maintained in that region than in the observed. It is well known that the tropical eastern Pacific is located in the downdraft branch of the tropical Walker circulation. As such, convection in this region is not as rigorous as that in the tropical western Pacific, which is located in the updraft branch of the tropical Walker circulation. The most important physical processes in the tropical eastern Pacific, perhaps, are those related to the shallow cumulus clouds in the subtropical trade wind inversion area. These clouds are known to efficiently transport moisture out of the subtropical boundary layer, thereby making this moisture available for horizontal transport into the tropical convergence zone for deeper cumulus clouds (Tiedtke et al., 1988). Based upon these physical processes, we propose that shallow convection activity in the GFS simulation may not induce sufficient vertical mixing for the transport of moisture out of the subtropical boundary layer into the tropical eastern Pacific. Without a sufficient moisture supply, GFS precipitation over the eastern-Pacific ITCZ is weaker in magnitude than the observed. However, this suggestion needs to be further investigated.

\section{ZONAL MEAN STATE}

Here, the simulated and analyzed zonal mean components of temperature and zonal wind fields are examined. In this work, we study the climate characteristics of the GFS in the troposphere. To this effect, all the latitude-pressure cross-section maps show the region between $1000 \mathrm{mb}$ and $100 \mathrm{mb}$.

\subsection{Zonal Mean Temperature}

The zonal mean components of climatological temperature field for the GFS simulation [denoted as $T_{z}$ (GFS)] and the NCEP data [denoted as $T_{z}$ (NCEP)] for the winter and summer seasons are shown in Fig. 5. Overall, the $T_{z}(G F S)$ field is in good agreement with the $T_{z}(N C E P)$ field in terms of spatial structure and magnitude for both winter and summer seasons. Also included in Fig 5 are the difference fields, $T_{z}$ (GFS) minus $T_{z}$ (NCEP), which are denoted as $T_{z}$ (GFS-NCEP). The difference fields reveal that there is, to a great extent, a cold bias in the simulated temperature field when compared to the analyzed. The simulated zonal mean temperature is $1^{\circ} \mathrm{K}-4^{\circ} \mathrm{K}$ colder than the analyzed throughout much of the tropospheric domain bounded by $40^{\circ} \mathrm{S}$ and $40^{\circ} \mathrm{N}$, but up to $8^{\circ} \mathrm{K}-18^{\circ} \mathrm{K}$ colder in the vicinity of the polar tropopause. The difference fields also make evident some warm biases in the GFS simulation over the upper-level extratropical regions and the lower-level polar regions of the winter hemisphere 

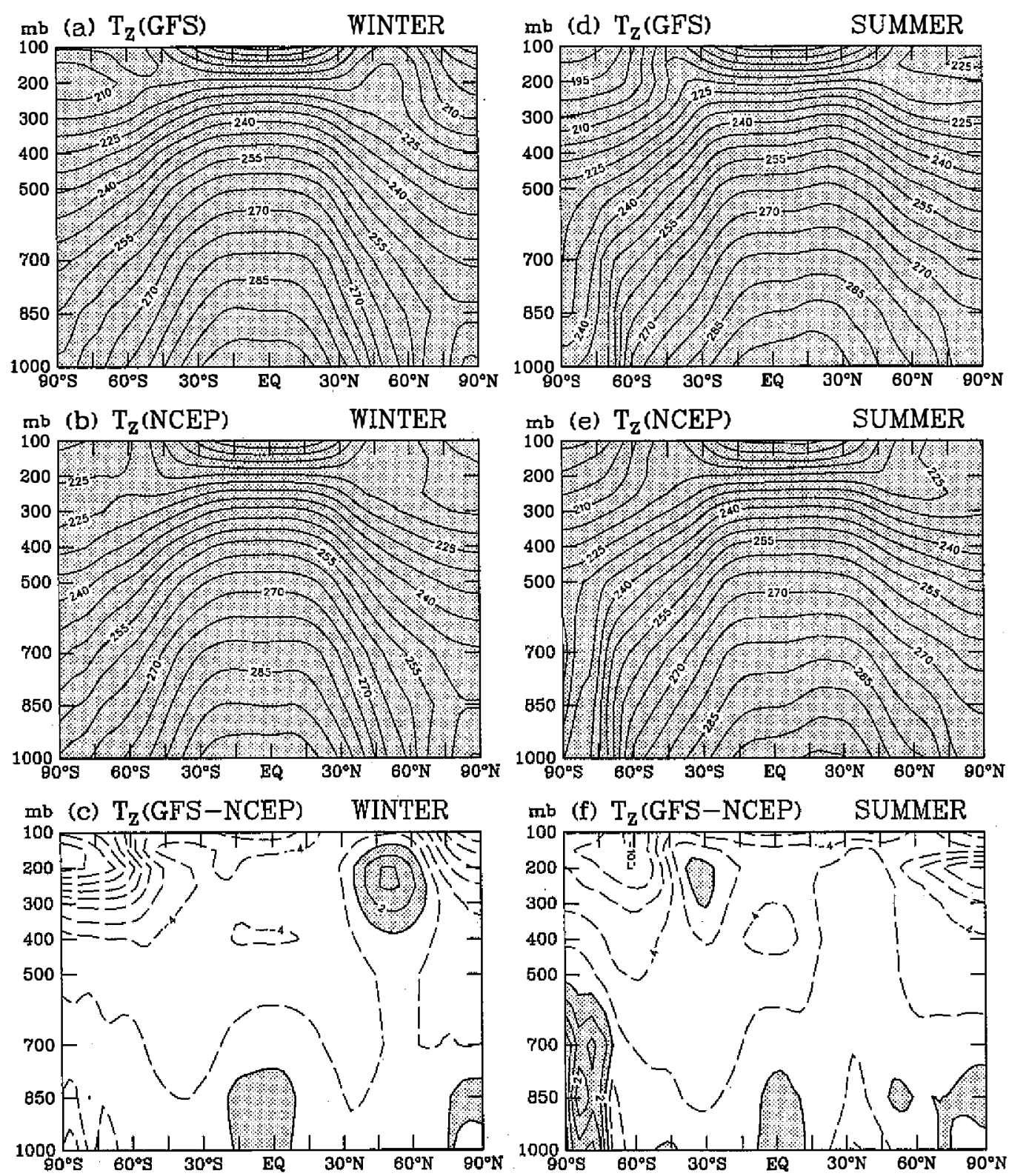

Fig. 5. Latitude-pressure cross-section maps of the zonal mean temperature $\left(\mathrm{T}_{z}\right)$ field. The winter climatologies of (a) $\mathrm{T}_{2}(\mathrm{GFS})$; (b) $\mathrm{T}_{2}$ (NCEP); and (c) $\mathrm{T}_{z}(\mathrm{GFS})$ minus $\mathrm{T}_{z}(\mathrm{NCEP})$ field $\left(\mathrm{T}_{z}\right.$ (GFS-NCEP)) are displayed in the panel on the left. The panel on the right includes the summer climatologies of (d) $\mathrm{T}_{\mathrm{z}}$ (GFS); (e) $\mathrm{T}_{\mathrm{z}}$ (NCEP); and (f) $\mathrm{T}_{\mathrm{z}}$ (GFS-NCEP). Contour intervals are $5^{\circ} \mathrm{K}$ in (a), (b), (d), and (e), and $2^{\circ} \mathrm{K}$ in (c) and (f). Positive temperature values are shaded. 
(i.e., $\mathrm{NH}$ in winter and $\mathrm{SH}$ in summer). Nevertheless, the warm biases are smaller in magnitude and spatial size than the cold biases.

These findings reveal that there is a significant cold bias at the polar tropopause in the GFS simulation. The problem of a cold polar tropopause was often found in previous climate simulation studies (e.g., Bore et al., 1992; Hurrell et al., 1993), and the existence of a cold bias indicates smaller heating content in the model atmosphere than in the observed. To correct such a model bias, ways must be found to heat up the model atmosphere. As illustrated by the $\mathrm{CCM}$, the global diabatic heating is mainly composed of radiative heating and latent heat, with the former contributing a net cooling effect and the latter a net warming effect (Boville 1985). These results suggest that one possible way to correct the cold bias problem is to incorporate a more effective convection parameterization scheme in the model. As tested by Hack (1994), the use of a more effective convection scheme in the CCM did help to moisten and warm the model troposphere. However, the impact mentioned above is more or less limited in the low latitudes and even becomes insignificant in the polar areas. The problem of a cold polar tropopause continues to be a major deficiency in climate simulation, including the GFS control simulation in this study.

\subsection{Zonal Mean Zonal Wind}

Figure 6 shows the winter and summer climatologies of zonal mean zonal wind $\left(U_{z}\right)$ for the GFS simulation [denoted as $\mathrm{U}_{\mathrm{z}}(\mathrm{GFS})$ ], NCEP data [denoted as $\mathrm{U}_{\mathrm{z}}(\mathrm{NCEP})$ ], and the difference between them $\left[\mathrm{U}_{\mathrm{z}}(\mathrm{GFS})\right.$ minus $\mathrm{U}_{\mathrm{z}}(\mathrm{NCEP})$, denoted as $\left.\mathrm{U}_{\mathrm{z}}(\mathrm{GFS}-\mathrm{NCEP})\right]$. In both winter and summer, salient features of the $U_{z}(\mathrm{NCEP})$ field, such as the subtropical jets in both hemispheres and the easterly jets in the tropics, are well represented in the GFS simulation. Nevertheless, the $\mathrm{U}_{z}$ (GFS-NCEP) fields in Figs. $6 \mathrm{c}$ and $6 \mathrm{f}$ reveal some systematic discrepancies between the simulated and analyzed $U_{z}$ fields. These appear to be more significant in the upper troposphere, particularly in the winter hemisphere (i.e., $\mathrm{NH}$ in winter and $\mathrm{SH}$ in summer). Moreover, the vertical structure of the $\mathrm{U}_{z}$ (GFS-NCEP) field tends to be barotropic in the middle and high latitudes in both winter and summer, but exhibits a clear phase change around $400 \mathrm{mb}$ in the low latitudes in summer. One more interesting feature to note is the spatial relationship between the $\mathrm{U}_{z}\left(\right.$ GFS-NCEP) and $\mathrm{T}_{z}$ (GFS-NCEP) fields. In winter, each of the major westerly wind biases in the upper troposphere, like the one centered at about $45^{\circ} \mathrm{S}$ or $65^{\circ} \mathrm{N}$ (Fig. 6c), is sandwiched by a relatively cold bias on the poleward side and a relatively warm bias on the equatorward side (Fig. 5c). For the major easterly wind bias, the bias in the upper troposphere centered at about $40^{\circ} \mathrm{N}$ is accompanied by a relatively cold bias on the equatorward side and a relatively warm bias on the poleward side. In summer, major zonal wind biases (Fig. 6f) include the westerly wind biases centered at about $50^{\circ} \mathrm{S}$ and $50^{\circ} \mathrm{N}$ and the easterly wind biases in the tropics. Similar to case of the winter simulation, the major easterly (westerly) wind bias in the summer simulation is accompanied with a relatively warm (cold) bias on the poleward side and a relatively cold (warm) bias on the equatorward side. The spatial relationship between the zonal wind and temperature bias fields can be summarized as follows: westerly (easterly) wind is situated in a thermal background with a meridional temperature gradient decreasing poleward (equatorward). This spatial relationship is consistent 

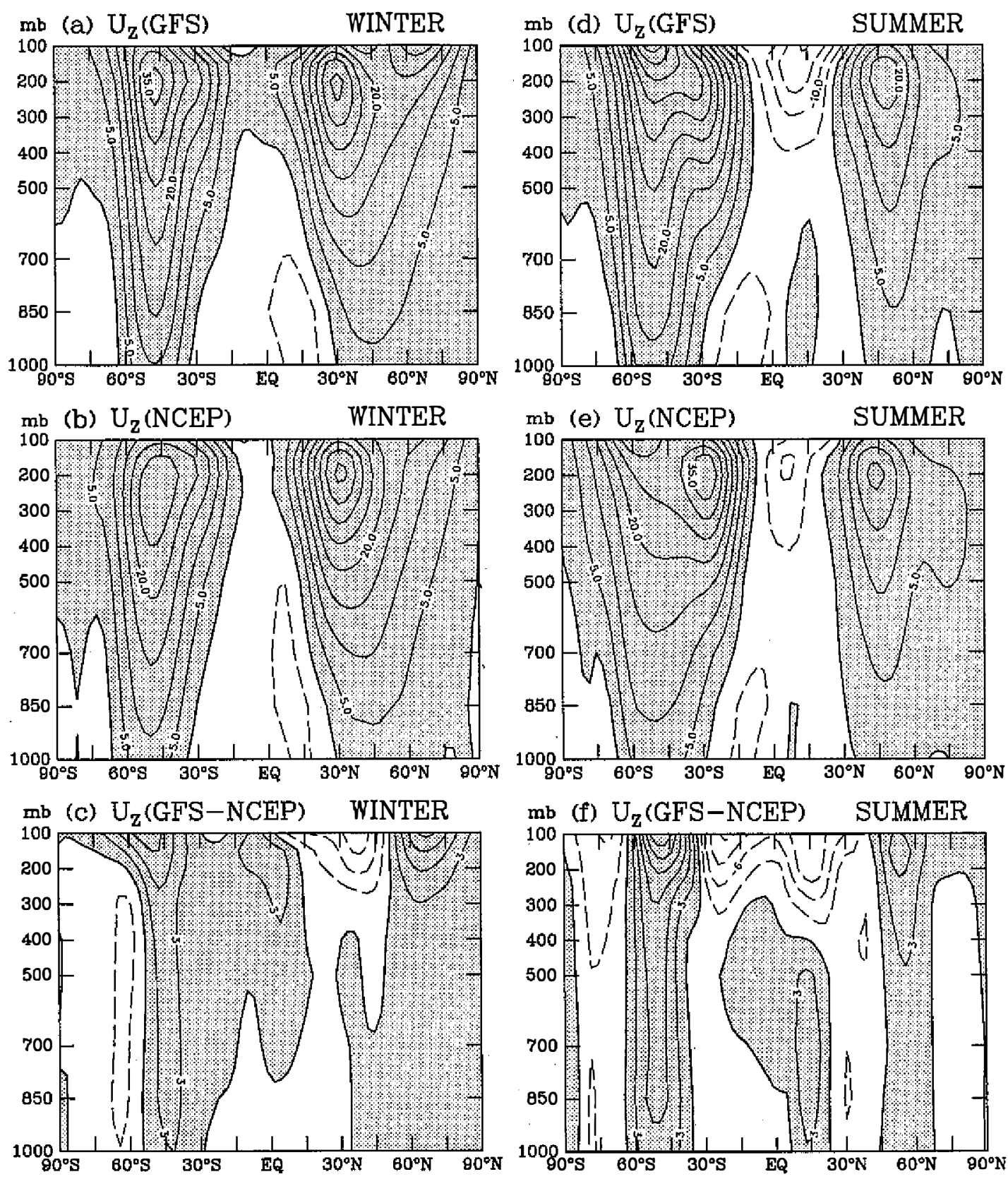

Fig. 6. As in Figure 5, except for the zonal mean zonal wind $\left(\mathrm{U}_{\mathrm{z}}\right)$ field. Contour intervals are $5 \mathrm{~m} / \mathrm{s}$ in (a), (b), (d), and (e), and $3 \mathrm{~m} / \mathrm{s}$ in (c) and (f). Positive zonal wind values are shaded. 
with the spatial relationship between the observed zonal wind and temperature fields, which is commonly known as the thermal wind relationship. These results suggest that interactions between the dynamic and thermal fields in the GFS simulation are, to a great extent, consistent with the real atmosphere with regard to the thermal wind relationship.

\section{GLOBAL CIRCULATION PATTERN}

Sea level pressure (SLP) and streamfunction fields at $850 \mathrm{mb}$ and $200 \mathrm{mb}$ are employed in this section to depict the global circulation pattern. Subsequent to the analysis of the zonalmean state in the previous section, the analysis here focuses on stationary eddy represented by the eddy component of streamfunction.

\subsection{Sea Level Pressure}

Figure 7 shows the winter and summer SLP climatologies for the GFS simulation and the NCEP data. In winter, the broad tropical low-pressure zone associated with the active tropical convection is well captured by the GFS. The subtropical highs to the west of the SH continents are simulated adequately with regard to position and magnitude by the GFS when compared to analyses. However, the simulated NH subtropical highs over the eastern Pacific and the eastern Atlantic are about 4-6 mb larger in magnitude than the analyzed. In the extratropics, the SLP field exhibits a zonal feature in the SH, but an eddy feature in the NH. In the SH extratropics, the broad low-pressure zone associated with the circumpolar Antarctic trough over the $60^{\circ} \mathrm{S}$ $70^{\circ} \mathrm{S}$ region is well represented in the GFS simulation. In the NH extratropics, the major SLP features, such as the Aleutian low over the northem Pacific, the Icelandic low over the northem Atlantic, and the continental highs over Asia and North America, are well positioned in the GFS simulation. Among these extratropical SLP features, the simulated Aleutian low is not as deep as the analyzed showing a difference of about $4 \mathrm{mb}$ in the center west of the date line. Moreover, its spatial structure is not sufficiently elongated far eastward into the Alaska/Canadian coasts when compared with the analyzed. As in the case of the simulation of the Aleutian low, the Icelandic low simulated by the GFS is not as deep as the analyzed having a difference of about $4 \mathrm{mb}$ in the center west of Iceland. On the other hand, the simulated continental highs over Asia and North America are about 3-6 mb stronger in their centers than the analyzed.

In summer, the major features of the analyzed SLP field, such as the wavenumber-2 feature in the NH and the zonal feature in the SH, are reasonably represented by the GFS in the large-scale sense. In the NH, the wavenumber- 2 feature of the SLP field is composed of subtropical highs over the North Pacific and the North Atlantic and thermal lows over Asia and North America. With regard to the pressure in the center of the SLP system, both simulated subtropical highs are about 4-6 mb larger than the analyzed, while the simulated thermal lows over Asia and North America are, respectively, $8 \mathrm{mb}$ and $20 \mathrm{mb}$ deeper than the analyzed. This indicates that the NH wavenumber- 2 feature of the SLP field is amplified in the GFS simulation when compared to the analyzed. In the $\mathrm{SH}$, the subtropical high-pressure zone is well positioned by the GFS but is nonetheless about $4-8 \mathrm{mb}$ stronger than the analyzed. The circumpolar Antarctic trough in the $60^{\circ} \mathrm{S}-75^{\circ} \mathrm{S}$ region is also well positioned by the GFS but is 

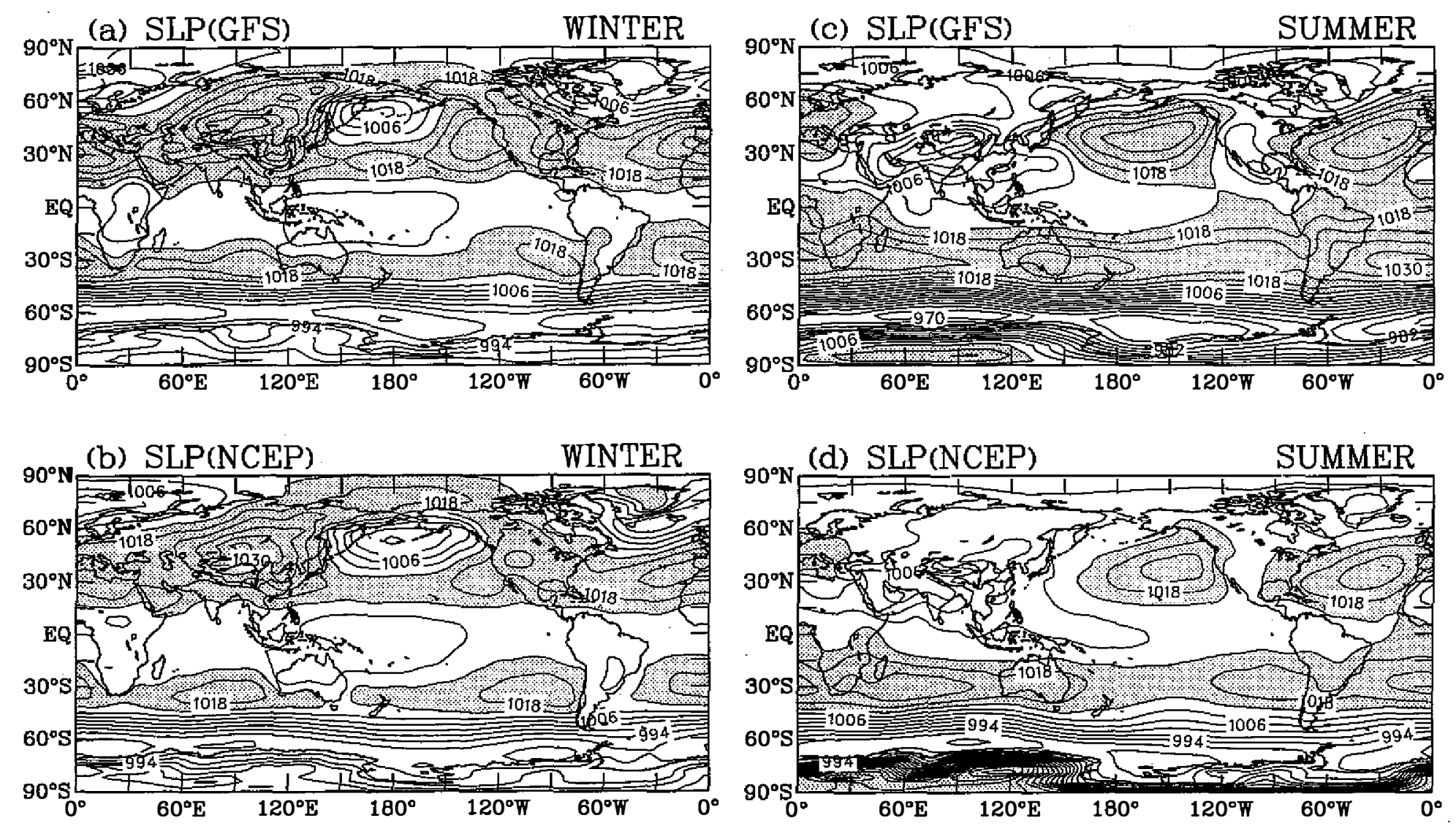

Fig. 7. Global SLP patterns for (a) the GFS winter climatology; (b) the NCEP winter climatology; (c) the GFS summer climatology; and (d) the NCEP summer climatology. All contour intervals are $4 \mathrm{mb}$. SLP values larger than $1014 \mathrm{mb}$ are shaded. 
about 12-16 mb deeper than the analyzed. These findings reveal that in the SH the GFS simulates a stronger subtropical high-pressure zone and a deeper circumpolar Antarctic trough relative to the analyzed. These SLP biases intensify the meridional pressure gradient and thus lead to overestimates of the surface westerly flows in the model SH midlatitudes. This conclusion is supported by the existence of a surface westerly wind bias in the $40^{\circ} \mathrm{S}-60^{\circ} \mathrm{S}$ region of the $U_{z}($ GFS-NCEP) field (Fig. 6f).

\subsection{Winter Eddy Streamfunction}

The winter climatologies of eddy streamfunction $\left(\psi_{\mathrm{E}}\right)$ at $850 \mathrm{mb}$ and $200 \mathrm{mb}$ for the GFS simulation and the NCEP data are presented in Fig. 8. In the large-scale sense, the GFS simulation captures the major spatial features of the analyzed $\psi_{\mathrm{E}}$ fields well. For the horizontal feature, the teleconnection pattern over the Pacific-North America (PNA) region, which is characterized by distinct low- and mid-latitude circulation regimes with a polarity reversal at about $30^{\circ} \mathrm{N}$, is simulated reasonably well by the GFS when compared to the analyzed. This PNA teleconnection pattern is more organized and pronounced at $200 \mathrm{mb}$ than at $850 \mathrm{mb}$. For the vertical feature, the GFS $\psi_{E}$ fields in the tropics exhibit basically the reverse circulation pattern between the lower- and upper-tropospheric fields. In a different manner, the GFS $\psi_{E}$ fields in the midlatitudes show a clear baroclinic feature. More specifically, the upper-tropospheric lows and highs are located west of their lower-tropospheric counterparts. These vertical features simulated by the GFS in the tropics and midlatitudes are in good agreement with the analyzed. This conclusion is supported by the pattern correlations between the simulated and analyzed $\psi_{E}$ fields, which is 0.77 for $850 \mathrm{mb}$ and 0.84 for $200 \mathrm{mb}$. Accordingly, it may be inferred that the GFS has an approximate $80 \%$ level of accuracy in simulating the winter stationary eddies portrayed by the NCEP data.

The major discrepancy between the simulated and analyzed $\psi_{\mathrm{E}}$ fields seems to be in magnitude. In the SH, the positive $\psi_{E}(850 \mathrm{mb})$ center and negative $\psi_{E}(200 \mathrm{mb})$ center over South America are underestimated by the GFS when compared to the analyzed, while the positive $\psi_{E}(850 \mathrm{mb})$ center and negative $\psi_{\mathrm{E}}(200 \mathrm{mb})$ center in the vicinity of Madagascar off the east coast of Africa are overestimated. Such circulation biases may be linked to the biases of heating source or precipitation. By examining the winter P(GFS-XA) field shown in Fig. 2c, it is found that over South America the underestimate of the circulation system in the GFS simulation is accompanied by an underestimate of in-situ precipitation. Over Madagascar, the overestimate of the circulation system is accompanied by an overestimate of local precipitation.

There are also some noticeable differences between the simulated and analyzed $\psi_{\mathrm{E}}$ fields in the NH. At $200 \mathrm{mb}$, the extratropical low-subtropical high doublets near the east coasts of the Asian and North American continents, which sandwich the respective East Asia and North America subtropical jet features, are well positioned in the GFS simulation. Even so, a comparison between the GFS and NCEP $\psi_{E}(200 \mathrm{mb})$ fields reveals that the low-high doublet over East Asia is underestimated in the GFS simulation, while the doublet over North America is overestimated. The underestimate of the former results in a weaker meridional streamfunction gradient between the extratropical low and subtropical high, thereby causing the underestimate of the East Asia subtropical jet features sandwiched by this low-high doublet. In accor- 

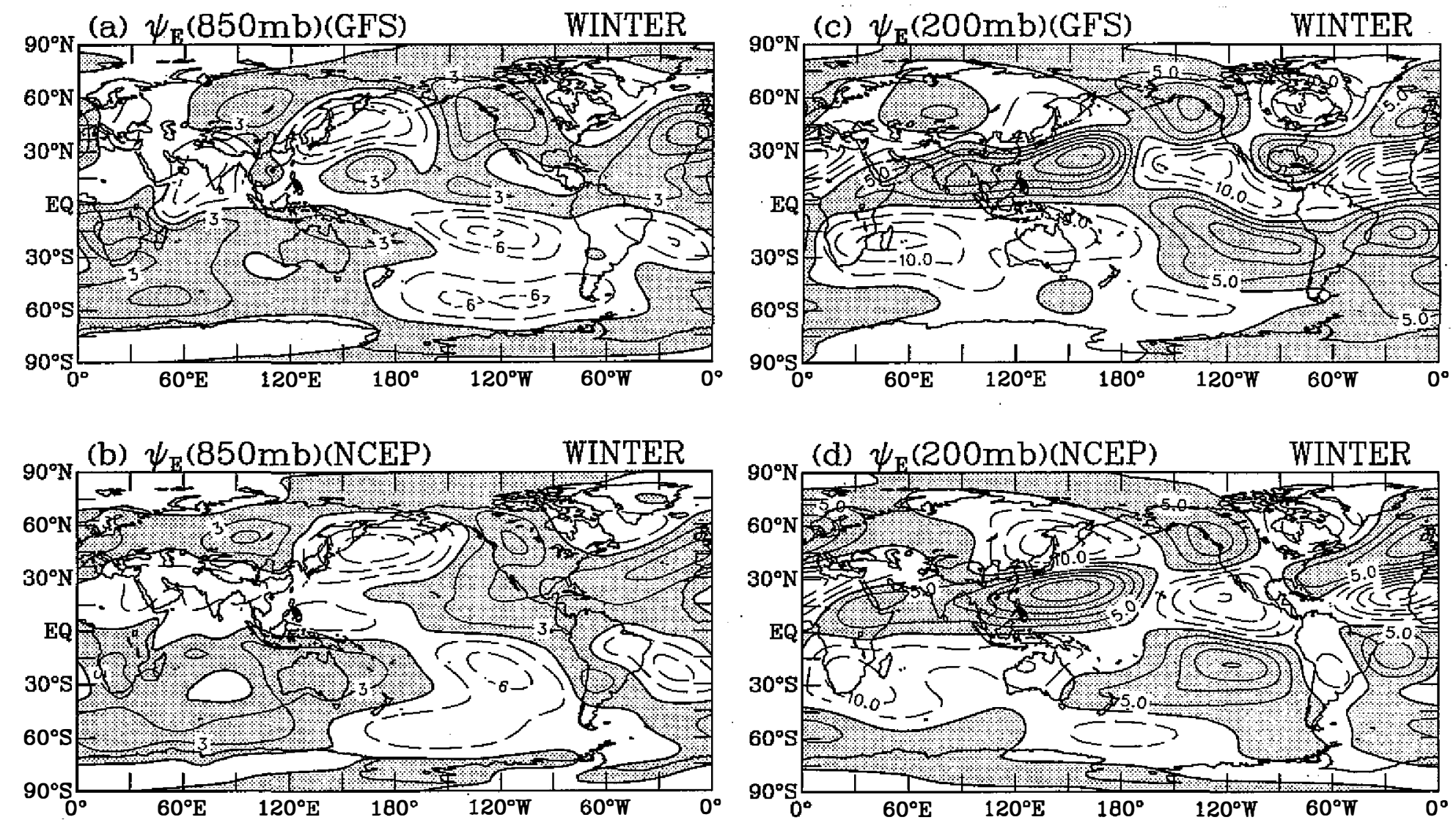

Fig. 8. Global pattems of the winter eddy streamfunction $\left(\psi_{E}\right)$ for the GFS simulation at (a) $850 \mathrm{mb}$ and (c) $200 \mathrm{mb}$, and for the NCEP data at (b) $850 \mathrm{mb}$ and (d) $200 \mathrm{mb}$. Contour intervals are $3 \times 10^{6} \mathrm{~m}^{2} / \mathrm{s}$ in (a) and (b) and $5 \times 10^{6}$ $\mathrm{m}^{2} / \mathrm{s}$ in (c) and (d). Positive $\psi_{\mathrm{E}}$ values are shaded. 
dance with the overestimate of the North America low-high doublet, it can be inferred that the North America subtropical jet features in the GFS simulation should be stronger than the analyzed

\subsection{Summer Eddy Streamfunction}

Illustrated in Fig. 9 are the $850 \mathrm{mb}$ and $200 \mathrm{mb}$ summer $\psi_{E}$ climatologies for the GFS simulation and NCEP data. As for horizontal structure, the most salient feature of the NCEP $\Psi_{E}$ field is a wavenumber-2 feature dominated by the low-latitude circulation regimes, a feature which is well simulated by the GFS. In the lower troposphere, the wavenumber- 2 feature of the $\psi_{\mathrm{E}}(850 \mathrm{mb})$ field in the $\mathrm{NH}$ is composed of thermal lows over the Asian and North American continents and subtropical highs over the North Pacific and the North Atlantic. These NH circulation systems are paired with the opposite-polarity circulation systems across the equator in the SH. In the upper troposphere, the $\psi_{\mathrm{E}}(200 \mathrm{mb})$ field also exhibits a wavenumber-2 feature with a spatial structure similar to that seen in the $\psi_{E}(850 \mathrm{mb})$ field, but with reversed polarity. The reversal in polarity of the horizontal pattern between the $200 \mathrm{mb}$ and $850 \mathrm{mb} \psi_{E}$ fields illustrates the dominance of monsoon systems in the summer climate. To evaluate the degree of resemblance between the simulated and analyzed summer $\psi_{\mathrm{E}}$ fields, we compute the pattern correlations between these fields at 0.91 for the $\psi_{\mathrm{E}}(850 \mathrm{mb})$ field and 0.90 for the $\psi_{E}(200 \mathrm{mb})$ field. Based upon these high pattern correlations, it is concluded that the summer monsoon circulation systems depicted by the NCEP data are well reproduced in the GFS simulation.

Despite the similarity in the large-scale structure, the simulated and analyzed $\psi_{\mathrm{E}}$ fields differ to some extent in magnitude. At both $850 \mathrm{mb}$ and $200 \mathrm{mb}$, the simulated $\psi_{E}$ fields are generally larger in magnitude than the analyzed. Over North America, the $850 \mathrm{mb}$ thermal low and $200 \mathrm{mb}$ Mexican high are simulated with stronger intensity than in the NCEP analyses. Mean while, the $850 \mathrm{mb}$ Pacific subtropical high and $200 \mathrm{mb}$ Pacific oceanic trough in the GFS simulation are amplified and distorted with a less pronounced southwest-northeast orientation than the analyzed. Over the North Atlantic, the 850 subtropical high and $200 \mathrm{mb}$ oceanic trough are also amplified in the GFS simulation when compared to the analyzed. These results imply that the wavenumber- 2 component of the simulated $\psi_{\mathrm{E}}$ field in the $\mathrm{NH}$ is stronger in intensity than the analyzed. It was pointed out by Ting (1994) that summer circulation structure is primarily determined by the distribution of latent heat released by ropical precipitation. This suggests that in the climate simulation the amplification of summer circulation should be related to the excessive precipitation bias. Accordingly, the summer P(GFS-XA) pattem shown in Fig. 3c is examined and two major excessive precipitation biases are found, one being over the subtropical centralNorth Pacific west of the date line and the otherover the Central Americal Caribbean Sea region. Each of these precipitation biases is accompanied by an 850 continental thermal low to the west and an $850 \mathrm{mb}$ oceanic subtropical high to the east and is located on the equatorward side of the aforementioned $850 \mathrm{mb}$ circulation systems. This systematic spatial relationship suggests that in the GFS simulation amplification of the $\mathrm{NH}$ wavenumber-2 components of the $\psi_{\mathrm{E}}$ field is likely linked to the excessive precipitation biases over the subtropical central North Pacific west of the date line and the Central America/Caribbean Sea 

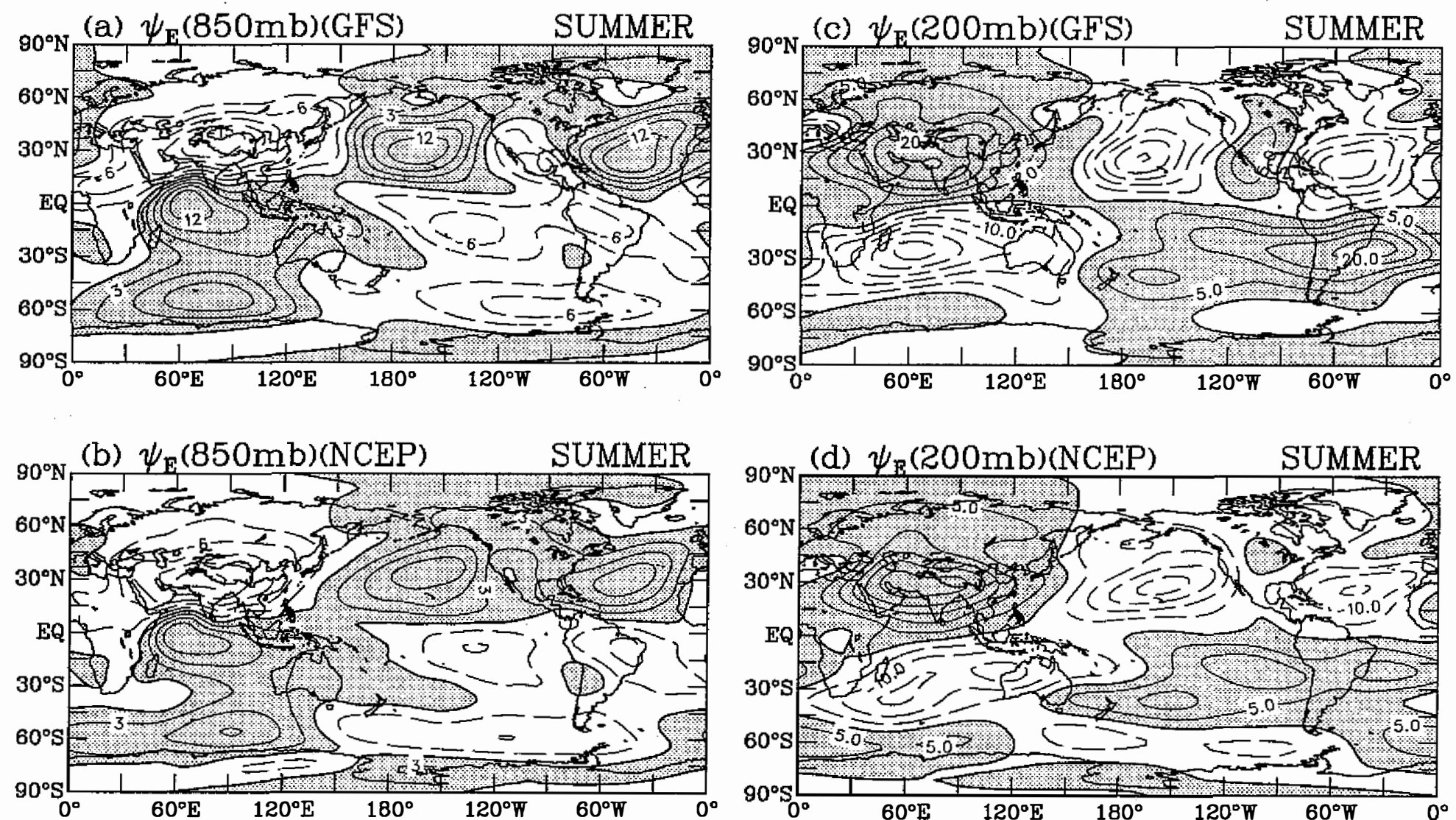

Fig. 9. As in Figure 8, except for the summer climatologies of the eddy streamfunction for the GFS simulation and the NCEP data. 
region.

Another important issue is related to the simulation of the lower-tropospheric Pacific subtropical high. It is well known that characteristics of the Pacific subtropical high are crucial in that it affects typhoon activity over the northwestern Pacific. Since large-scale circulation simulated by the GFS at the CWB is employed as the background field in the typhoon track forecast model to predict typhoon movement, errors in the GFS circulation, especially the Pacific subtropical high, must affect the accuracy of typhoon movement forecasts. A comparison of Figs. 9a and 9b shows that the simulated Pacific subtropical high is not sufficiently extended southwestward toward the subtropical western Pacific when compared with the analyzed. At the CWB, such a shape error in the GFS Pacific subtropical high is likely to result in errors in the forecast of the recurving movement of a typhoon in the vicinity of the subtropical westem Pacific. In addition to this, the GFS Pacific subtropical high is overestimated in magnitude and is thus accompanied by stronger tropical trade winds than the analyzed. Such a wind bias is likely to cause inaccuracies in the forecast of the westward movement of a typhoon along the tropical Pacific. In order to reduce such possible forecast errors, the capability of the GFS to model the spatial pattern and magnitude of the Pacific subtropical high must be improved.

\section{CONCLUDING REMARKS}

This study documents the climate characteristics of the Global Forecast System (GFS), which is an atmospheric general circulation model developed at the Central Weather Bureau, Taiwan. The characteristics of winter (December-February) and summer (June-August) climatologies are presented from a 2-year control simulation conducted with the GFS. The work focuses on the aspects of hydrological processes and atmospheric circulation. The GFS simulation results are validated against the observed precipitation estimates of Xie and Arkin (1996) and the NCEP reanalysis data.

Regarding the climate characteristics of hydrological processes, the major features of observed precipitation, such as the ITCZ, the SPCZ, the Asian monsoon regimes, and the extratropical storm tracks, are well represented in the GFS simulation. Other observed precipitation features, like the regions of low precipitation rates over the subtropical subsidence zones and polar areas, are also well reproduced by the GFS. Discrepancies between the observed and simulated precipitation fields, however, tum out to be more significant in the tropics. Several excessive precipitation errors are found over some tropical regions where there are complex topographic variations between oceans and lands. Other than these overestimated regions, the GFS precipitation in the remaining tropical areas is generally underestimated when compared to the observed. In particular, the eastem-Pacific ITCZ strip simulated by the GFS is weaker in intensity and less organized in spatial structure than the observed. This precipitation deficiency is associated with less convergence of water vapor flux into the tropical eastern Pacific in the GFS simulation. In a different manner, discrepancies between the simulated and observed precipitation fields are not evident in the extratropics. In other words, the extratropical precipitation simulated by the GFS is more consistent with the observed when compared to 
tropical precipitation. Despite the above discrepancies in the spatial structure of precipitation, the total amount of precipitation (as inferred from global mean precipitation) simulated by the GFS is rather close to the observed amount, showing only a $2 \%$ error.

Regarding the climate characteristics of the zonal mean state, the zonal mean climatologies of temperature and zonal wind are reasonably well reproduced by the GFS when compared with analyses. Nevertheless, the most noticeable systematic bias in the model zonal mean temperature field is a cold bias over much of the tropospheric domain. This cold bias is generally within $4^{\circ} \mathrm{K}$ of the analyzed in the low and middle latitudes, but becomes significant in the vicinity of the polar tropopause, where the model temperature is about $8^{\circ} \mathrm{K}-18^{\circ} \mathrm{K}$ colder than the analyzed. The bias pattern of the zonal mean temperature exhibits the following spatial relationship with the bias pattern of the zonal mean zonal wind: westerly (easterly) wind is situated in a thermal background with a meridional temperature gradient decreasing poleward (equatorward).This spatial relationship is consistent with the spatial relationship between the observed temperature and zonal wind fields, which is commonly known as the thermal wind relationship.

Regarding the climate characteristics of atmospheric circulation, the simulated atmospheric circulation system, which is depicted by the fields of SLP, the $850 \mathrm{mb}$ eddy streamfunction, and the $200 \mathrm{mb}$ eddy streamfunction, is in reasonable agreement with the analyzed. In particular, the principle features of the analyzed atmospheric circulation, such as the summer monsoon system and winter teleconnection pattern, are well captured by the GFS. On the other $h$ and, there are some systematic errors in model atmospheric circulation. In winter, the subtropical jet features over East Asia are underestimated, whereas the ones over North America are overestimated when compared to analyses. In summer, the $\mathrm{NH}$ wavenumber-2 components of the atmospheric circulation are simulated with larger magnitude by the GFS than the analyzed. The overestimate of the $\mathrm{NH}$ wavenumber- 2 components of atmospheric circulation is accompanied by two major excessive precipitation biases over the subtropical central North Pacific west of the date line and the Central America/Caribbean Sea region.

The analyses in this study demonstrate that climate characteristics of hydrological processes and atmospheric circulation simulated by the GFS are in reasonable agreement with the observations and analyses of the atmosphere. At the same time, however, our analyses illustrate some systematic biases in the GFS climate states. It goes without saying that those need to be corrected and fine tuned in the future.

The work to document the climate characteristics of the GFS in this study is merely one part of many efforts to develop a climate model at the CWB. As an operational center, the CWB needs its own climate model to do research and make predictions for climate change because climate changes have a great impact on a large variety of human activities. Certainly, the most obvious candidate for the development of a refined CWB climate model is the GFS. As such, we expend continuous efforts to study the climate characteristics of various aspects of the GFS as well as to find possible ways to reduce model systematic biases. With these endeavors, we hope to develop a more elaborate CWB climate model that can accurately and reliably reproduce the actual atmospheric state. 
Acknowledgements We would like to extend our appreciation to all our colleagues who have developed, refined and maintained the GFS model. Thanks also go to Dr. Jui-Lin (Frank) $\mathrm{Li}$ and the anonymous reviewers for their comments that help to clarify the issues discussed in this study. The editorial assistance provided by Mr. Joel Newson is appreciated. The GFS control simulation was conducted with the CWB CRAY supercomputer.

\section{REFERENCES}

Arakawa, A., and W. H. Schubert, 1974: Interaction of a cumulus cloud ensemble with the large-scale environment, Part I. J. Atmos. Sci., 31, 674-701.

Bengtsson, L., and A. J. Simmons, 1983: Medium range weather prediction - operational experience at ECMWF. In Large Scale Dynamical processes in Atmosphere, B. J. Hoskins and R. P. Pearce (Eds.), Academic Press, 337-363.

Bore, G. J., and Coauthors, 1992: Some results from an intercomparison of the climates simulated by 14 atmospheric general circulation models. J. Geophy. Res., 97, 12771-12786.

Boville, B. A., 1985: The thermal balance of the NCAR Community Climate Model. J. Atmos. Sci., 42, 695-709.

Deser, C. and J. M. Wallace, 1990: Large scale atmospheric circulation features of warm and cold episodes in the tropical Pacific. J. Climate, 6, 1743-1753.

Detering, H. W., and D. Etling, 1985: Application of the E-e turbulence model to the atmospheric boundary layer. Bound.-Layer Meteor., 33, 113-133.

Gates, W. L., 1992: AMIP: The atmospheric model intercomparison project. Bull. Ame. Meteor. Soc., 73, 1962-1970.

Hack, J. J., 1994: Parameterization of moist convection in the National Center for Atmospheric Research community climate model (CCM2). J. Geophy. Res., 99, D3, 55515568.

Hack, J. J., B. A. Boville, J. T. Kiehl, P. J. Rasch, and D. L. Williamson, 1994: Climate statistics from the National Center for Atmospheric Research community climate model CCM2. J. Geophy. Res., 99, D10, 20785-20813.

Harshvardhan, R. Davies, D. Randall, and T. Corsetti, 1987: A fast radiation parameterization for atmospheric circulation models. J. Geophys. Res., 92, 1009-1016.

Hollingsworth, A. K., K. Arpe, M. Tiedtke, M. Capaldo and H. Saavijarvi, 1980: The performance of a medium-range forecast model in winter - Impacts of physical parameterizations. Mon. Wea. Rev., 108, 1736-1773.

Hoskins, B. J., and D. J. Karoly, 1981: The steady linear response of a spherical atmosphere to thermal and orographic forcing. J. Atmos. Sci., 38, 1179-1196.

Hurrell, J. W., J. J. Hack, and D. P. Baumhefner, 1993: Comparison of NCAR Community Model climates. NCAR Tech. Note NCAR/TN395+STR, 335pp. [Available from NCAR, Boulder, CO 80307.]

Jeng, B.-F., H.-J. Chen, S.-C. Lin, T.-M. Leou, M. S. Peng, S.-W. Chang, W.-R. Hsu, and C.P. Chang, 1991: The limited-area forecast systems at the Central Weather Bureau in Taiwan. Wea. Forecasting, 6, 155-178. 
Kalnay, E., and Coauthors, 1996: The NCEP/NCAR 40-year reanalysis project, Bull. Ame. Meteor. Soc., 77, 437-471.

Kasahara, A., 1982: Nonlinear normal mode initialization and the bounded derivative method. Rev. Geophys. Space. Phys., 20, 385-397.

Kasahara, A., and A. P. Mizzi, 1985: Preliminary evolution of diabatic heating distribution from FGGE level III-b analysis data. Proc. First National Workshop on the Global Weather Experiment, National Academy Press, Washington, D.C., Vol. 2, Part I, 317 329.

Lau, K.-M., J. H. Lim, and Y. Sud, 1996: Intercomparison of hydrological processes in AMIP GCMs. Bull. Ame. Meteor. Soc., 77, 2209-2227.

Liou, C.-S., J.-H. Chen, C.-T. Temg, F.-J. Wang, C.-T. Fong, T. E. Rosmond, H.-C. Kuo, C.H. Shiao, and M.-D. Cheng, 1997: The second-generation global forecast system at the Central Weather Bureau in Taiwan. Wea. Forecasting, 12, 653-663.

Louis, J. F., 1979: A parametric model of vertical eddy fluxes in the atmosphere. Bound.Layer Meteor., 17, 187-202.

Mo, K. E., and Higgins, R. W., 1996: Large-scale atmospheric moisture transport as evaluated in the NCEP/NCAR and the NASA/DAO reanalysis. J. Climate, 9, 1531-1545.

Monin, A. S., and A. M. Obukhov, 1954: Basic regularity in turbulent mixing in the surface layer of the atmosphere. Akad. Nauk. SSR Trud. Geofiz. Inst. Tr., 24, 163-187.

Moothi, S., and M. J. Suarez, 1992: Relaxed Arakawa-Schubert: A parameterization of moist convection for general circulation models. Mon. Wea. Rev., 120, 978-1002.

Palmer, T. N., G. Shutts, and R. Swinbank, 1986: Alleviation of a systematic westerly bias in general circulation and numerical weather prediction models through an orographic gravity wave drag parameterization. Quart. J. Roy. Meteor. Soc., 112, 1001-1039.

Peng, M. S., B.-F. Jeng, and C.-P. Chang, 1993: Forecast of typhoon motion in the vicinity of Taiwan during 1989-1990 using a dynamic model. Wea. Forecasting, 8, 309-325.

Simmons, A. J., 1982: The forcing of stationary wave motion by tropical diabatic heating. Quart. J. Roy. Meteor. Soc. 108, 503-534.

Simmons, A. J., and R. Strufing, 1981: An energy and angular momentum conserving finitedifference scheme, hybrid coordinates, and medium-range weather prediction. ECMWF Tech. Rep. 28, 68pp. [Available from European Center for Medium-Range Weather Forecasts, Shinfield Park, Reading RG2 9AX, United Kingdom.].

Tiedtke, M., 1984: The sensitivity of the time-scale flow to cumulus convection in the ECMWF model. ECMWF's Workshop on Convection in Large-Scale Numerical Models, ECMWF, Reading, United Kingdom, 297-316. [Available from European Center for Medium-Range Weather Forecasts, Shinfield Park, Reading RG2 9AX, United Kingdom.]

Tiedtke, M., W. A. Heckley, and J. Slingo, 1988: Tropical forecasting at ECWMF: The influence of physical parameterization on the mean structure of forecasts and analysis. Quart, J. Roy. Meteor. Soc., 114, 639-664.

Ting, M., 1994: Maintenance of northern summer stationary eddies in a GCM.J. Atmos. Sci., 51, 3286-3308. 
Xie, P., and P. A. Arkin, 1996: Analyses of global monthly precipitation using gauge observations, satellite estimates, and numerical model predictions. J. Climate, 9, 840-858. 